\title{
Philip dos civilizados, o selvagem da selva de pedra
}

Cláudia Rodrigues de Freitas*

\section{Resumo}

Este artigo analisa os modos de organizar a vida e aprendizagens de um menino em situação de sofrimento psíquico e desamparo social, a partir do momento em que é atendido em um espaço escolar. A experiência envolve a tessitura de redes de conversações entre aqueles que convivem com Philip, um menino encaminhado ao Atendimento Educacional Especializado (AEE), a partir do diagnóstico de autismo, uma das formas de dizer no campo do Transtorno Global de Desenvolvimento (TGD). O espaço de acolhimento proposto teve como intenção ampliar a forma de viver e de aprender de Philip. As intervenções surgem e se desenham a partir da invenção do brincar e se tornam visíveis no encontro do olhar, no sorriso, no manuseio dos objetos da vida comum e, fundamentalmente, na interação com as pessoas ao seu entorno. A inserção e invenção do/no espaço educativo tem o propósito de transformar o sofrimento em vida e possibilidades de aprendizagem. O resultado deste trabalho forja transformações estruturais na convivência entre Philip e todos aqueles em interação com ele. Redes de conversação, quando tecidas em rizoma, permitem a construção de saberes capazes de sustentar outro modo de viver.

Palavras-chave: Inclusão escolar; Educação Especial; Atendimento educacional especializado; Transtorno global de desenvolvimento.

* Professora Doutora da Universidade Federal do Rio Grande do Sul (UFRGS). Porto Alegre, Rio Grande do Sul, Brasil. 


\section{Philip dos civilizados: the wild boy from stone jungle}

\section{Abstract}

This article analyzes the ways of organizing life and the learning processes of a boy experiencing psychic distress and social abandonment from the moment he receives care at a school facility. The experience involves the organization of a network of conversations among those who live with Philip, a boy who was referred to the Special Education Services (SES) based on the autism diagnosis, one of the disorders in the category of Pervasive Developmental Disorders (PDD). The assistance center proposed was aimed at expanding the way of living and learning of Philip. The interventions come up and develop themselves from the invention of playing and become visible through eye contact, smiles, when handling objects that are part of everyday life and mainly by interacting with people around him. The insertion and invention of/in the educational space is aimed at transforming the suffering in life and learning possibilities. The result of this work creates structural transformations in the coexistence between Philip and all the individuals that interact with him. When consolidated conversation networks enable the construction of knowledge areas that are able to support another way of living.

Keywords: School Inclusion; Special Education; Special Education Services; Pervasive Developmental Disorders.

\section{Introdução}

O sujeito se faz no encontro. Ao trabalhar na área de Atendimento Educacional Especializado (AEE), encontrei Philip. Ele vive o desencontro, habita o espaço de fora. A franja do convívio. Mora em uma instituição referida como sendo para "pessoas vegetativas". A partir deste nome, qual o lugar de quem ali habita? O que lhe empresta de significado este espaço como moradia? As perguntas encontram o viver do menino até então definido pela cama/casa. E, agora, surge a intenção de buscar espaço na escola. Não estamos falando de qualquer garoto. Philip encontra nomeação a partir do diagnóstico de autismo, uma das formas de dizer no campo do Transtorno Global de Desenvolvimento (TGD). Palavras demarcam, conceituam, rotulam, sujeitos assim definidos historicamente encontram terreno movediço quanto à possibilidade de escolarização. Assim, esta história sofre uma reviravolta quando, aos doze anos, o menino encontra a escola.

Moradia e diagnóstico imprimem discussões sobre a possibilidade de escolarização do menino. Ele é encaminhado ao Atendimento Educacional Especializado (AEE), espaço de acolhimento proposto com a intenção de garantir a aprendizagem. Ao longo do texto, as intervenções surgem e se desenham no brincar, no sorriso, no manuseio dos objetos da vida comum e, fundamentalmente, na interação com as pessoas ao seu entorno. 
Acredito existir um caminho conceitual ligando a floresta onde foi encontrado Victor de Aveyron e a Selva de Pedra, forma da vida de nosso tempo. Local de selva: a instituição que, a princípio, oferecia o vazio de humanidade. Como ferramenta de referência, tomo os escritos de Itard e dos que a partir dele escrevem sobre o garoto selvagem. Referência ainda são os que pensam o viver compartilhado, o aprender como possibilidade de todos.

A semelhança entre o garoto selvagem de Itard e do caso trabalhado por mim não está nas ações pedagógicas, mas na ambientação, na Selva. Para Victor a selva, final do século XVIII e início do XIX, era concreta, real. Deixar uma criança na floresta, seja por ser considerada deficiente ou por ser ilegítima era possível e legitimada, normalizada, nas práticas naquele momento histórico. "A verdade é deste mundo" diz Foucault (1992, p. 13). Sim e a cada tempo são produzidas outras formas de viver a franja do convívio. Os sujeitos que incomodam o olhar e as formas de convivência definidas como as adequadas devem encontrar um espaço para estar.

Segundo Leite (2000, p. 11), "crianças que, tendo permanecido longe do contato com a civilização, se tornaram conhecidas como selvagens". Sim, desde os relatos, Victor esteve afastado deste convívio por muitos anos. E Philip? Onde encontra atalho para a floresta de Victor? Ao olhar para a suposta casa onde mora o protagonista desta história, encontro um menino vivendo a nova selva. Foucault $(1993)^{2}$, refere-se à forma de exclusão, de colocar para fora do convíveo em nosso tempo como sendo através da exclusão pela inclusão. É a produção de "cajones", novos gavetões: instituições nas quais se segue inventando lugares para alguns e deixando outros na franja do convívio. É a selva produzida em nosso tempo.

Sim, Philip tem alimento e está protegido da chuva, mas o que mais têm do viver humano? Quem mora em uma Instituição para vegetativos conversa? Pensa? Sente? Quem pergunta a ele? Quem sabe dele? Quando vence as grades de um metro de altura de sua cama, imediatamente alguém o devolve ao mesmo espaço. Há lugar para palavras. Sabe caminhar, mas não pode! O que o faz impedido? Encontro Philip em um estado que me faz escutar Luis (2000, p. 39), ao referir Victor: "um menino em estado de selvagem". Isolado do convívio. Não sabe comer com a mão ou usar os dentes. É alimentado com papas. Engole. Sua mão não sabe pegar. Não sabe pegar!

As palavras de Itard ecoam em mim ao olhar para o menino que chega aos doze anos a escola: "seu estado atual não é a causa de seu abandono, mas seu efeito. É a falta de necessidades sociais o que condicionou seu escasso desenvolvimento; é, portanto, educável." (LUIS, 2000, p. 43)

Em estado de abandono - não há mais selva de árvore disponível, mas seguem as selvas institucionais. O vazio do convívio humano. A indisponibilidade para a acolhida e a ensinagem do encontro e dos afetos. A palavra se aprende desde quem anuncia o manhes ${ }^{3}$. Sua família, o abandonou na Selva de Pedra, restou a ele a institucionalização em uma "casa para vegetativos".

Os relatórios de Jean Itard sobre o processo de desenvolvimento e de educação do menino Victor do Aveyron permitem aprofundar a reflexão sobre os efeitos da privação do contato social sobre o

Revista Educação Especial | v. 27 | n. 49 | p. 431-446| maio/ago. 2014

Santa Maria 
desenvolvimento humano. O estado em que foi encontrado o menino, depois de vários anos vivendo isolado na floresta, deixa patente a condição animal social do homem que, para se construir como ser humano precisa viver entre os humanos. (GALVÃO; DANTAS, 2000, p. 83) Grifo meu.

Philip, após sua chegada a instituição, recebe o que a selva atual lhe oferece. Não está incluída a possibilidade do convívio. "Viver com, Vive ao lado". Transitam entre as camas pessoas que não se mostram como tal. Apenas o suporte básico para a sustentação do orgânico, mas somos mais. Em algum momento, uma cuidadora da instituição reconhece em Philip a possibilidade de aprender. Em movimento de arauto - não sem antes travar batalha dentro da instituição - leva o garoto até a escola.

\section{Da Selva para a "civilização", um safari além das grades}

La condición fundamental de la existencia es la confianza

[...] Cuando una semilla se humedece y comienza a germinar, lo hace confiando en la presencia de todos los nutrientes necesarios que posibilitarán su crecimiento ulterior. Y también cuando nace un bebé, éste confía plenamente en que tendrá una madre y un padre que se preocuparán de su bienestar. Pero esta confianza implícita en que se funda la existencia de todos los seres vivos es defraudada permanentemente: las flores son envenenadas con insecticidas, el broteno recibe suficiente agua, y el bebé que llega al mundo como un ser amante, no es amado y no es visto, sino que es negado en su existencia. Afirmo que la constante negación del otro genera enfermedades [...]. (MATURANA, 2004, p. 228)

Atendimento Educacional Especializado, essa modalidade atravessa o fazer escolar. Ao trabalhar nesta área, cruzei com Philip e as narrativas de seu viver. Este encontro permitiu observar transformações na convivência e experienciar um novo pensar em relação a estes sujeitos. Batizei-o ficticiamente como Philip Patrik Colombo, buscando, neste nome e sobrenome, dar alusão a sua identidade real, a qual propõe "certa nobreza" na forma e faz pensar em "alguém importante". Philip de fato constrói importância em mim.

Durante os últimos 10 anos tive a oportunidade de conviver com crianças e adolescentes moradores de instituições muito peculiares e funcionam de tal forma que a palavra oral praticamente não existe. Poucos caminham, vários são mantidos por tubos, "as papas" são o alimento de quase todos. O ir a uma escola é absolutamente uma novidade, esburacando a lógica de uma destas instituições a partir de Philip. A possibilidade de sair de lugares asilares desta ordem marca a mudança da instituição, assim como o da escola e fazem deles, arautos de outros modos de existência na relação com o aprender e o ensinar.

Retomo um pouco da história de Philip que constrói seu processo de encontro quando procura atendimento em uma Escola Especial Municipal na cidade de Porto Alegre. Tinha na época 12 anos, morando em uma instituição dedicada a pessoas "totalmente dependentes de terceiros nas atividades de vida diária". Sim, de fato Philip 
correspondia a esta indicação. Caminhava sem parar. Não usava as mãos, o banheiro ou mesmo a palavra - forma de comunicação mais usada na vida comum. Comunicava-se pelo olhar! Philip, de modo semelhante a "Victor de Aveyron", empregava a "linguagem de ação" (BANKS-LEITE, 20000, p. 67) e, assim, se fazia entender. A intuição da cuidadora que o trazia a escola estava recheada de saber, cuidado e aposta. Ele era o primeiro que trazia a escola e logo fiquei sabendo ter uma lista sob a manga.

\title{
Movimento Inicial, abrindo uma clareira na selva
}

Como movimento inicial a Escola ${ }^{4}$ oferece turmas compatíveis a idade cronológica. As tentativas não foram promissoras e a escola busca uma alternativa para a permanência de Philip. Na época, eu trabalhava na Escola com o atendimento a crianças pequenas 5 . Philip não fazia parte da "idade" costumeira de crianças atendidas por mim. Propus, então, inventar um novo espaço que chamei de "Acolhimento". A ideia era de fato acolher a Philip como marca da possibilidade de escolarização.

A proposta era a de ampliar e consolidar a possiblidade de inclusão escolar. Quando, há mais de uma década, Kupfer (2001, p. 72) referindo-se a inclusão dizia:

\begin{abstract}
[...] evidentemente, não são as crianças com vida vegetativa e amarradas a uma cama cheia de tubos que estamos recebendo em nossas escolas a partir das novas políticas públicas e pedagógicas de inclusão escolar. Essas estão excluídas da inclusão, o que já mostra que nem mesmo a inclusão é para todas.
\end{abstract}

Não sabia ela, assim como eu, de Philip, Luísa, Laura, Maria, Antônio e tantos outros que de lá para cá fazem "borrar" os limites da inclusão e transformam a escola em espaço de invenção permanente. A entrada de Philip, na escola, evidencia uma lógica sempre em movimento de transição. Crianças provindas de espaços como esse passam a frequentar AEE, Escola Especial e Escola Comum.

Desencadeia-se algo da ordem da invenção:

O que propomos é a ideia de invenção como obra aberta, esforço coletivo que não tem autor. Para o seu desenvolvimento contribuem múltiplas mãos, múltiplas forças. Entendemos esse processo como um rizoma, um atravessamento. O embate dessas forças produz outras trilhas, fendas, aberturas. A invenção convida; está em movimento; ela não tem fim, não tem obra pronta, criada. Cada enfrentamento dá pistas para novos movimentos, continuamente. (EIZIRIK et al, 2001, p. 75)

Como seres humanos, nascemos capazes de aprender e construir conhecimento. Essa não é a capacidade de nos adaptarmos ao mundo, mas de inventá-lo. Invenção como ato único produzido por cada sujeito. Kastrup (2005, p. 1.273) faz uma diferenciação entre criação e invenção na relação com a cognição. Segundo ela, a criação seria uma capacidade de resolver problemas, "uma capacidade de produzir soluções originais para os problemas", onde o crédito é dado ao sujeito, ou a partir do criador. A invenção consistiria em um movimento de "invenção dos problemas", tendo um caráter complexo de construções em um movimento de imprevisibilidade com relação ao próximo passo. 
Philip é o caso foco que tomo, neste momento, entre outros pela intensidade e novidade ao ingressar na escola. A "construção deste caso" ajuda a tornar imprecisas as fronteiras através das quais os alunos seriam "beneficiados" pela inclusão escolar e qual o "resto" se encontraria além da franja.

\section{Traçando o mapa: o que sabia de Philip}

Quando iniciei a montagem dos dados sobre Philip, observei muitos deles se contradizendo. Em momentos diferentes, eu tinha anotado dados, uns em relação aos outros. Data de nascimento, época em que começou a andar, pela mão de quem chegou à instituição, etc. Os dados foram trazidos por pessoas diferentes e até aí se justificava as disparidades, mas fiquei mais intrigada quando, também, as mesmas pessoas, em momentos diferentes, traziam informações contraditórias. O "engano" não parecia apenas meu, a orientadora da escola também tinha anotado dados em desalinho.

Para entender o que se passava, voltei a "casa" de Philip e me debrucei sobre sua pasta, seus registros (ou melhor, dizendo, os registros dos "outros" sobre ele). Passo a passo, fui recolocando as peças do quebra-cabeça. Na certidão, descobri duas datas: a de nascimento e a de registro. Entre uma e outra, um ano e três meses de diferença. Ele só foi registrado após sua internação em estado grave em um hospital da cidade.

Os registros de hospitalização contam de um tempo de internação no hospital de 20 dias. Os motivos descrevem um bebê com diarreia e desidratação de $2^{0}$ grau. Contam ainda que ele foi entregue a instituição onde mora com um ano e cinco meses, levado pela mãe: "não tinha estrutura para cuidar do filho".

Philip, como qualquer bebê, nasce na confiança de que alguém o acolherá, amamentará e protegerá. Em uma época na qual a cidade oferece uma vasta rede pública de atendimento hospitalar, Philip nasce em casa. Os relatos de sua pasta contam de "sequelas por asfixia perinatal". Não tenho notícias de seu tempo antes do parto, mas sei que sua chegada não foi organizada de forma a receber a proteção necessária. Somente após sua internação a mãe o registra e não consta na certidão a identidade paterna. Esta é relatada em seus registros na instituição, mas não se fez presente no momento de preencher a certidão. Seu pai não lhe empresta identidade, não lhe reconhece. Este dado não é passível de passar como menor, pois o casal vive junto e tem outros filhos. Não se trata desta forma da ausência do companheiro. Fica evidente a ausência de uma paternidade garantida.

As várias evidências falam de um bebê/menino constituído no desamparo ${ }^{6}$, na lei da selva, a qual vem the negando identidade e filiação.

Difícil saber o que se estabeleceu de fato, mas a marca da ausência de "tudo" é a história de Philip. Foi negado a ele o pertencimento familiar e mesmo o alimento básico, pois, quando foi internado, estava em estado grave de desnutrição. Foi lhe negado acolhida em ambiente de confiança. A marca do desamparo não pode ser descrita apenas por Philip. Reconheço nos fatos iniciais uma família construída nesta situação, mas vou me ater neste momento apenas no que isso lhe afeta de forma direta. Philip 
surpreendentemente, e diferente de quase todos na instituição onde mora, "caminha sem parar". Em sua casa permanece todo tempo na cama, mas na escola caminha "sem rumo". O Rumo... Fomos aprendendo aos poucos a perceber, sentir e produzir.

Aproximo, aqui, uma conexão entre o não parar e o desamparo saltando em forma de brincadeira com as palavras. Não parar e desam(paro) formam um nexo de existência que não é coincidência. O (desam)paro é constituído pelo paro. Ele está no desamparo. Outra conexão ainda seria a do (des)amparo, na qual o prefixo "des" tem valor de oposição quando se liga ao verbo amparar. O que ampara, protege, auxilia, sustenta, passa a estar funcionando em oposição a sua origem. A gramática revela o que, no viver, está evidente: o não parar se constrói junto com o desamparo. Há uma conexão do que não para com o desamparo. Elas estão ligadas desde a formulação da(s) palavra(s).

\section{A "Nova Selva"}

A selva/floresta onde foi encontrado Victor de Aveyron, floresta de La Cune em 1799 (LEITE e GALVÂO, 2000) e aquela que chamo de "Nova Selva" se assemelham muito em suas cartografias. Quando Itard encontra Victor existiam "selvas de árvores". Lugares escondidos e pouco frequentados por humanos e servindo, por vezes como espaço para deixar, largar, abandonar crianças que se supunham deficientes. Este ato tinha o acordo tácito da comunidade da época.

Hoje, temos outras formas de selva, de esconder do olhar o que não queremos ver ou não podemos conviver. Foucault (1996, p. 114), refere-se "à reclusão que aparece no século XIX, que tem por função ligar os indivíduos aos aparelhos de produção, formação, reformação ou correção de produtores. Trata-se, portanto de uma inclusão por exclusão". Não era mais possível jogar para fora, e o que se passa a fazer é incluir. Incluir os sujeitos em alguém "uma série de instituições - escolas, fábrica, etc." (ibid, $115)$

A aproximação desliza em semelhanças. A nova selva na qual é deixado Philip não lhe oferece muito além do alimento e "teto". A instituição reconhecida aqui como a "Mãe Selva", mãe perversa (sem mesmo o saber ou querer ser). Philip e todos os "internos" usam um macacão de flanela em baixo da roupa. Este macacão impede a possibilidade do contato direto com seu corpo. Ele é usado inverno e verão com uma ideia explicita: "é para não cair às fraldas... Para que não mexam no cocô". Não é permitido mexer na merda, na sexualidade e no instituído. Já que não podem aprender ninguém ensina o uso do banheiro.

Desde a década de 20, não se ouve descrições de crianças selvagens, entretanto Banks-Leite (2000) retoma esta denominação referindo-se às circunstâncias do contemporâneo:

Se, pela expressão Selvagem, entende-se até agora o homem pouco civilizado, concordar-se-á que aquele que não o é de maneira nenhuma merece mais rigorosamente ainda essa denominação. Portanto, conservarei para este o nome pelo qual sempre o designaram, até que eu tenha explicado os motivos que me determinaram a dar-lhe um outro. (BANKS-LEITE, 2000, p. 130) 
É preciso rever conceitos e recolocar, no contemporâneo, aquilo apresentado como selva, como o que não oferece a sustentação na cultura. Do descrito por estas palavras não diferencio o lugar onde encontro Philip.

Mais uma aproximação, agora de potencia de devir: Victor encontra Itard e Philip a Sueli. O olhar de Sueli, cuidadora da instituição, que faz reconhecer em Philip um sujeito, uma pessoa. Até então, tínhamos um selvagem em uma selva, a do contemporâneo, do mundo civilizado. Sueli reconhece no menino um sujeito. O olhar dela busca a inserção dele na escola com vistas à "socialização". Disputa na instituição a ideia um Philip que demonstra "potencial".

Acerca do confronto entre crianças selvagens e crianças com autismo, sabemos apenas que há semelhanças entre esses sujeitos. Ademais é muito provável que várias crianças selvagens tenham sido abandonadas em função da presença de dificuldades ou limitações evidentes. (BAPTISTA, 2001, p. 94)

\section{Philip chega à escola}

Philip é trazido do "Lar Nossa Senhora da Selva dos Civilizados" para buscar matrícula na Escola Especial. O selvagem chega pela "mão" da cuidadora, a qual imagina a escola como espaço para ele.

[...] a escola é um lugar para entrar e sair. É um lugar de trânsito. Além do mais, do ponto de vista da representação social, a escola é uma instituição normal da sociedade, por onde circula, em certa proporção, a normalidade social. Portanto, alguém que frequenta a escola se sente geralmente mais reconhecido socialmente do que aquele que não frequenta. (JERUSALINSKY, 2004, p. 150)

Entendo o espaço da escola como marca da infância, na qual a experiência de vida e a possibilidade de espelhamento ensinam e fazem crescer. Pertencer a um espaço pedagógico, do ponto de vista de representação social, propõe um lugar de criança, e não o de diferente. Disputa a cuidadora com a diretora da instituição, pois esta acredita inicialmente "ser este um gasto desnecessário". Sueli insiste e acrescenta: "poderiam construir uma pracinha para ele [...]". "Aprendemos existir" quando encontramos espelho no olhar do outro que nos acolhe em atenção e escuta.

Para construir uma relação fortalecida com o menino, solicito ser sempre a mesma pessoa responsável por trazer Philip aos atendimentos. Sueli rapidamente toma como sua esta tarefa. Ela acaba por participar de quase todos os atendimentos e vamos aprendendo a conhecer Philip. Sueli em posição de encontro refere: "Sabe, eu vi o jeito que tu trata com ele e agora eu não levanto mais ele do chão. Procuro conversar e ver o que ele está querendo".

A Selva, enquanto instituição, não reconhecia a pertinência de alguém que oferecesse aos sujeitos ali algo de sentimento de piedade e cuidados de "sobrevivência" do corpo que não sente ou pensa. Estes pareciam não demandar nada além do alimento e troca de fraldas. 
Busquei investir no encontro com a cuidadora. O desafio posto está em preencher este menino de imaginário, de histórias, de mundo. Porque fora da cultura não temos a convivência, o laço com o outro. O espelhamento permitido é uma mimis, expressão usada, aqui, no sentido de misturados, de tal forma a não permitir o espaço para a dúvida, diferença ou o estranhamento.

\section{Os contornos na selva: mapeando a instituição}

Multiplicavam-se as informações sobre a instituição onde morava Philip. Falavam em camas como cela, grades... Um Philip que ficava todo o tempo deitado... Eu não podia entender como isso se dava e precisei conhecer o lugar. Nunca em meu percurso como professora tinha ido a uma "Instituição para Vegetativos".

Portão aberto e vários carros estacionados. Terreno irregular e uma construção semelhante a uma casa. Entro e me identifico. Depois de uma breve apresentação sou levada ao quarto de Philip. Sua cela/casa/cama ${ }^{7}$ fica em um quarto junto a muitas outras, todas com grades altas - talvez um metro de altura. A cama, casa, cela de Philip são o mesmo espaço. Ele apenas sai dali para ir à escola ou tomar banho. Este lugar desafiava meu olhar a compreendê-lo, a tentar absorver a complexidade, o paradoxo presenciado por mim naquele dia.

Do "vegetativo" deitado na cama, vejo um menino que levanta rápido ao som de minha voz e literalmente pula por cima da grade saltando em meu colo. Rapidamente me toma pela mão e passamos a circular/caminhar. Algumas vezes se senta no chão. $O$ rapaz que me acompanha pelo passeio, o agarra e levanta, ou o leva para o lugar onde supunha, deveria ir.

Philip não é apenas um organismo, um aparelho biológico. Fernandéz (2012) faz uma distinção entre organismo e corpo onde este é produzido na relação e no encontro. "O corpo atende porque se comove. E é aí que o pensar é convocado." (ibid, p. 48)

\section{As pistas da trajetória: as trilhas da selva}

O ato pedagógico, portanto, deveria deixar de ser uma decorrência do progresso diagnóstico, passando a integrar um movimento da investigação que explora a pergunta: quem é esse sujeito? (BAPTISTA, 2002, p. 95)

Philip, ao chegar para os atendimentos, caminha sem parar e, nas tentativas de acompanhar este trilhar, observo. Atira-se no chão em vários momentos. Não, não se atira: senta. Suponho este sentar como uma parada. Para por quê? Em movimento de entendimento de sua "parada" suponho uma interrupção da trajetória para tomar outro sentido e direção. Conto a ele sobre minha hipótese de entendimento:

Philip, estou achando que quando te atiras ao chão queres parar e tomar outra direção. Se tu queres ir para outro lugar é só tu puxar a minha mão. Eu paro. Nós podemos ir onde tu quiseres. Este momento é teu e eu posso ir a qualquer lugar contigo.

Revista Educação Especial | v. 27 | n. 49 | p. 431-446| maio/ago. 2014

Santa Maria 
Disponível a ele repito várias vezes esta fala, como se fosse sua guia nessa selva. Paro na busca do amparo e tentativa do encontro. Não tenho a intenção de levantá-lo a qualquer lugar. Peço que determine os movimentos de parada e se constitua em ação.

Pouco a pouco, ele o faz. Puxa-me pela mão e me redireciona o caminhar. Passa a olhar para dentro das salas de aula com ar de curiosidade. Duas professoras amorosamente deixam a porta aberta sempre que estou com ele. Philip olha, para, chega mais perto e entra algumas vezes com um ou dois passos para dentro. Em outros momentos, consegue entrar e fazer a volta na sala. Os colegas que aí se encontram, assim como a professora, o acolhem: - "Tudo bom Philip? Pode entrar. Olha o que estamos fazendo!"8

[...] a vida de uma criança transcende a sua existência individual, mas se conecta com o discurso social, e ali se encadeia, dele extraindo seu sentido. Mas essa medalha tem duas faces, e se uma é a do socius, a outra é a do sujeito em sua singularidade. Viver com os outros é o que constitui e tece, de modo estrutural, a teia e o tecido de um sujeito. Se algo na história de uma criança a está impedindo de enodar com o outro, de fazer laço social, então buscar o reordenamento simbólico desse sujeito, tratar dele é, entre outras coisas, levá-lo, mais uma vez, à trama social. Ao meio da rua, às escolas. (KUPFER, 2001, p. 77)

Reforço com minha palavra os convites: "Estás interessado no que eles estão fazendo, não é? Por que estão sentados? O que fazem com estas coisas sobre as mesas?". Este jogo encanta. Philip entra senta por breves instantes na mesa com os demais. Logo em seguida, coloca sua cadeira junto a pia e bebe água. Ensaios. Bebe com "os colegas". Alguns arriscam vir até a pia e beber com ele. Falam mesmo que a resposta não venha em palavras. Philip para e olha para o colega em movimento de aproximação. A cena descrita monta o sutil espaço entre escolarização e tratamento em processo de aliança. "Quanto ao termo "escolarização" colocada ao lado do "tratamento", há para isso uma explicação muito simples: escolarização é tratamento!" (KUPFER, 2000, p. 11). A atitude dos colegas inscreve Philip no lugar de criança/aluno. Esta preciosidade não é possível de ser conquistada, a não ser na relação, em ato. No encontro entre iguais. Nos fazemos sujeitos na relação!

Philip agora caminha sem mão pela escola. Em alguns momentos toma da minha e segue a caminhada, em outros apenas transita. Em um corredor, uma professora the oferece uma Bolacha Maria. Ele abre a boca e ela lhe ajuda a morder. Um novo começo! "Ele não come nada sólido", penso eu em voz alta. A professora se assusta, ao que eu digo: "Não, pode dar". Philip está no céu. Corre atrás da professora como forma de pedir mais. Sua tentativa de mastigação é estranha. Esta boca sabe engolir, mas não sabe ainda organizar sua porção de agressividade para mastigar o que se apresenta. Seus lábios não se fecham. Tudo é muito estranho pra ele. 


\section{Aprendendo a dizer com o corpo}

Philip espera a hora de comer de forma ansiosa. Em dado momento, me dá o tênis que costuma tirar ao entrar para a sala, assim posso entender ser esta a hora de ir ao refeitório. Ali, com os demais alunos: "Tem que sentar com os outros para receber o lanche. Bolo, bolacha, canjica, pãozinho... Merendas da escola”. Encantamento. Os colegas o cumprimentam: "Tudo bom Philip!"

A escola transformada em laboratório de conhecimento tornase um espaço de ação contínua, que deve substituir a reflexão como ato propulsor de avanço [...] não devemos simplesmente "delinear conclusões". A complexidade do objeto de análise exige o ato cauteloso de identificar avanços. (BAPTISTA, 2002, p. 137)

Philip descobre a mão pegando a comida. Esta mão a princípio não pegava nada, agora não deixa nada em seu lugar. Mexe em tudo, derruba, espalha. Trago chocolate e a surpresa aumenta. Coloco a "isca" dentro de uma casinha que abre o telhado. A mão, a princípio sem utilidade, agora não encontra alternativa a não ser abrir a tampa. A dificuldade vai aumentando: uma caixa dentro da outra até a enorme caixa de papelão. Ele abre a todas elas e toma de seu tesouro. Seus olhos não são os mesmos. E ele me olha com um novo brilho!

\section{Aprendendo a comer...}

Levo frutinhas e corto em pedaços pequenos. Coloquei açúcar sobre elas. Em sua casa as papinhas costumam ser muito doces - aproveito esta dica. Banana, mamão e morango. Tudo descascado e cortado na sua frente. Cheirado e esperado. Com o garfo, lhe entrego o primeiro pedaço. Philip joga depois o garfo no chão. Retomo: "Hoje tu vai segurar o garfo como os outros meninos". Seguro sua mão e mostro o movimento. Philip não larga o garfo, a não ser depois do último pedaço.

\section{Aprendendo a brincar...}

Monto torrezinhas com cubos empilháveis. Mostro como se derruba. Philip, esparramado ao chão e com parte do corpo sobre meu colo, estica a mão e derruba a torre "conforme eu ensinei". Sorrimos, vibramos. Estamos brincando! Fernández (2012, p. 18) refere "que quando a criança está brincando, a potência atencional da alegria conecta-a simultaneamente com o incomensurável de seu desejo e o mensurável do limite real que o mundo real lhe oferece".

\section{O encontro com o humano}

[...] quando foram encontradas, as meninas não sabiam andar sobre os pés, mas se moviam rapidamente de quatro. É claro que não falavam, e seus rostos eram inexpressivos. Queriam apenas comer carne crua, tinham hábitos noturnos, repeliam o contato dos seres humanos e preferiam a companhia de cachorros e lobos. (MATURANA, 2002) 
Esta história conta de duas meninas selvagens (1920), trazidas por uma expedição que massacrou os lobos com quem elas viviam, perto de um vilarejo no norte da Índia. Amala aparentava um ano e meio e morreu pouco menos de um ano depois. Kamala tinha mais de oito anos quando foi encontrada e sobreviveu por nove anos. A evolução de Kamala foi impressionante, mas não passou por um tratamento educacional e terapêutico.

Maturana ao comentar sobre as meninas indianas diz:

[...] embora em sua constituição genética a anatomia e a fisiologia fossem humanas, as duas meninas nunca chegaram a acoplar-se ao contexto humano. Os comportamentos que o missionário e sua família queriam mudar nelas, por serem aberrantes no âmbito humano, eram inteiramente naturais para as meninas lupinas. Na verdade, Mowgli, o menino da selva imaginado por Kipling, jamais poderia ter existido de carne e osso, porque sabia falar e comportou-se como um homem quando reconheceu o ambiente humano. Nós, seres de carne e osso, não somos alheios ao mundo em que existimos e que está disponível em nosso cotidiano. (MATURANA, 2002, p. 146)

Ainda hoje, estas experiências ajudam a pensar sobre o estar acolhido em redes de conversações é a condição para a manutenção do viver como humano. Todos os seres vivos vivem em torno deste ciclo. Esta é uma organização comum, entretanto nós humanos nos situamos como seres dotados de sistema nervoso e ainda de um modo particular de organizar o viver.

Itard imagina seu processo de educar a Victor como frustrado porque não aprendeu a falar e comportar-se como "os humanos", mas Victor falava! Aprendeu entre os humanos a ser humano. Victor cria a ideia de leite quando o outro lhe entrega o copo com o leite. Winnicott (1993) refere que o objeto é criado e não descoberto.

\section{Considerações finais: diário da selva}

[...] foi preciso torná-lo feliz à sua maneira, deixando-o ao ar do dia, oferecendo-lhe fartamente alimentos de seu gosto, respeitando sua indolência e acompanhando-o em seus passeios, ou melhor, em suas correrias ao ar livre, e isso fosse qual fosse o tempo que pudesse fazer. (BANKS-LEITE apud ITARD, 2000, 138)

Philip recebeu um olhar de acolhida e, a partir desta nova circunstância em seu viver, um conjunto de transformações se produz e implica a todos os que com ele convivem; em especial a mim. Professora e aluno se transformam em congruência. Inventam-se como ensinante e aprendente no sentido oferecido por Fernandez (1990) onde o lugar do ensinante só se faz na medida em que ensina e aprende, e o aprendente se faz pelo mesmo processo, relativizando lugares, possibilitando a construção de conhecimento.

Antes mesmo de conhecer a Philip, já ouvia pelos corredores pessoas que me interpelavam dizendo: "Tu vais atender o Menino-Lobo? O menino Selvagem? Nossa, 
ele é igual ao Menino Lobo!" Menino Lobo, por quê? Ele avança? É selvagem? É menino por quê? Uma criança selvagem é aquela que assim se torna quando longe do contato com a civilização durante longo tempo. Este menino estava em uma selva? Em um "estado selvagem"? Quais os espaços podem ser vividos como selva no mundo de hoje? Como vive Philip?

Ao entrar na escola, encontra movimento de encontro comigo, com os alunos, professores, a rua. Encontra espaço de visibilidade em sua casa quando ganha a pracinha. O encontro com Philip permitiu o movimento instituinte de uma trajetória a ser inventada. Trata-se da oportunidade de viver a educação inclusiva como conceito e prática.

Philip se faz arauto. Um dia em visita a sua casa a cuidadora me diz: "Essa menina também precisava ir para a escola". Olho a pequena em um carrinho de bebê. Meu olho se engata no dela a partir da cuidadora. Ela foi a segunda. Hoje são mais três presentes na Escola Infantil e dois no ensino Fundamental. Uma das pequenas que chegou à escola com o diagnóstico de uma sídrome rara - de novo a síndrome chegou antes da menina - hoje está muito bem. A diretora refere: "Ela não é mais de "inclusão"' - palavra usada muitas vezes para referir os sujeitos para os quais escola se mostra com dificuldade de ensinar.

Conexão, surge uma pista, o trabalho em rede. O enlace da atuação entre cuidadores, Educadora Especial e Escola produzindo novos sentidos e possibilidades. E possibilitando a Philip, a tantos outros, uma conexão com o universo de experiências do aprender. Um caminho foi desbravado nessa selva, revelando possibilidades.

\section{Referências}

BANKS-LEITE, L.; GALVÃO, I. (Org.). A educação de um selvagem: as experiências de Jean Itard. São Paulo: Cortez, 2000.

BAPTISTA, C. R. Integração e autismo: análise de um percurso integrado. In: BAPTISTA, C. R.; BOSA, C. (Org.). Autismo e educação: reflexão e propostas de intervenção. Porto Alegre: Artmed, 2002, p. 127 -139.

BAPTISTA, C. R.; OLIVEIRA, A. C. Lobos e Médicos: primórdios na educação dos “diferentes”. In: BAPTISTA, C. R.; BOSA, C. (Org.). Autismo e educação: reflexão e propostas de intervenção. Porto Alegre: Artmed, 2002. p. $93-109$.

EIZIRIK, M.; FREITAS, C.; MAIA, D. A onda inclusiva. In: IIo Colóquio Invenção e Devires da Inclusão. Porto Alegre, Rio Grande do Sul, Gazeta do Empiria, 2001.

FERNÁNDEZ, A. A Atenção aprisionada. Tradução de HICKEL, N. e SORDI, R. O. Porto Alegre: Penso, 2012.

FREITAS, C. R. de. Arquipélago de Oásis: As Estratégias do aprender e a possibilidade de desconstrução de rótulos. Uma trilha possível nos caminhos da Inclusão. In: Tecendo Ideias na cidade que aprende - vol II. Porto Alegre, RS, Prefeitura Municipal de Educação - SMED, 2006.

FOUCAULT, M. A Verdade e as formas Jurídicas. Rio de Janeiro: NAU Editora, 1996.

. Microfísica do Poder. Rio de Janeiro: Graal, 1992.

JERUSALINSKY, A. Psicanálise e Desenvolvimento Infantil: um enfoque transdisciplinar. $3^{a}$ ed. Porto Alegre: Ed. Artes e ofícios, 2004.

Saber falar: como se adquire a linguagem? Ed. Vozes, 2008.

JERUSALINSKY, J. Enquanto o futuro não vem: a psicanálise na clínica interdisciplinar com bebês. Ed Ágalma, Salvador, Bahia, Brasil, 2002. 
KASTRUP, V. Políticas cognitivas na formação do professor e o problema do devir-mestre. In: Educação \& Sociedade, v. 26, n. 93, p. 1273-1288, 2005.

KUPFER, M. C. M. Editorial. In: KUPFER, M. C. M. (Org.). Tratamento e escolarização de crianças com distúrbios globais de desenvolvimento. Salvador: Ed. Ágalma, 2000.

Duas notas sobre a inclusão escolar. In: Escritos da Criança noㅡ 6. Porto Alegre: Ed. Centro Lydia Coriat, 2001.

MATURANA, H. R.; VARELA, F. J. A árvore do conhecimento: as bases biológicas da compreensão humana. Tradução de Humberto Mariotti e de Lia Diskin. São Paulos: Palas Athena, 2001.

MATURANA, H.; PÖRKSEN, B. Del ser al hacer - Los Orígenes de la Biología del Conocer, 2004.

PARLATO-OLIVEIRA, E. M. Os aspectos constitucionais do bebê na constituição do sujeito. In: COLÓQUIO DO LEPSI IP/FE-USP, 5., 2004.

PINHO, G. S. O Brincar na clínica interdisciplinar com crianças. In. Escritos da Criança no․ Ed Centro Lydia Coriat, Poro alegre RS, Brasil, 2001.

WINNICOTT, D. La natureza Humana. Buenos Aires, Paidós, 1993.

\section{Notas}

${ }^{1}$ Victor de Aveyron é o nome dado ao menino encontrado na floresta de Aveyron na França e levado a Paris onde passa a ser motivo de estudo de Itard. A tradução dos escritos do médico Jean Itard estão no livro de Banks-Leite e Galvão de 2000.

2 A referência tem o título de "A verdade e as Formas Jurídicas" (1996), livro baseado em cinco conferências que Michel Foucault proferiu na PUC do Rio de Janeiro, em 1973.

${ }^{3}$ Vários autores discorrem sobre o "manhês" como Severina Ferreira (2005), Alfredo Jerusalinsky (2008). Julieta Jerusalinsky (2002) discorre sobre a importância de "favorecer as aquisições instrumentais de um bebê [...] operamos quando tomamos seu balbucio como fala, seu sorriso como endereçado a alguém entre os presentes." (2002, p.229) Segundo Erika Parlato-Oliveira (2004) "O manhês é encontrado nas mais diversas comunidades culturais, e é produzido por um adulto que se ocupa do bebê, frequentemente sua mãe, mas que também pode ser produzido por qualquer outro que se ocupe desta função de maternagem. [...] A musicalidade prosódica da voz materna dirigida ao bebê, o manhês, marca a produção de linguagem do bebê e produz a escritura prévia de sua estruturação, nos permitindo, na clínica, identificar os sinais de adoecimento precoce do bebê." Pinho (2001, p.185) fala ainda sobre a função fundamental da linguagem como elemento que "inscreve o sujeito na ordem simbólica, possibilitando-lhe ingresso em determinada história, no interior de uma cultura. [...] Todo bebê, quando nasce, é mergulhado em um universo de linguagem. Esse "banho de palavras deixa marcas singulares em cada criança, que se inscrevem em seu corpo e lhe conferem uma significação mínima, fazendo com que o simbólico (a linguagem) venha recobrir o real (o corpo)".

${ }^{4}$ A Escola referida aqui é uma Escola Especial na cidade de Porto Alegre.

${ }^{5}$ Em Porto Alegre, desde o início da década de 1991, acontece o trabalho com bebês e crianças pequenas nomeado de Educação Precoce (EP) e Psicopedagogia Inicial (PI) como modalidade de atendimento que ocorre nas quatro Escolas Especiais existentes na Rede Municipal de Ensino - RME. A Psicopedagogia Este trabalho é uma forma de Atendimento Educacional Especializado (AEE) oferecido a bebês e crianças pequenas e caracteriza como uma intervenção pedagógica e terapêutica cuja proposta consiste em construir ferramentas com a criança para que esta possa apropriar-se dos objetos de conhecimento e, assim, poder aprender na Escola Infantil. Para maiores informações sobre este trabalho ver Freitas 2006.

"A noção de desamparo que trago não tem um compromisso com o que Freud denominou "mal-estar na civilização". Busco um entendimento livre onde desamparo é desenhado como uma produção social e cultural. O que chamo de desamparo é uma forma aguda de sofrimento que acaba por produzir uma existência de sofrimento. Forjado por um conjunto de dispositivos que funcionam como um processo de produção social da contemporaneidade. É uma forma aguda de padecimento do sujeito contemporâneo.

${ }^{7}$ Aqui mantenho o ato falho de primeira escrita - casa - retomando o texto de Itard ao se referir às Petites-Maisons. "Antigo hospício de Paris, assim chamado por causa das pequenas celas, ou casas, onde ficavam os loucos." (N. do T.) (Relatório de Jean Itard, 2000, p.137. in BANKS-LEITE).

${ }^{8}$ Este movimento da notícia de uma ferramenta usada neste trabalho: a ideia de Acompanhante terapêutico. Era assim que muitas vezes me sentia. Esburacando lugares junto com Philip na intenção de achar ali um lugar para ele. 


\section{Correspondência}

Cláudia Rodrigues de Freitas -Universidade Federal do Rio Grande do Sul, Faculdade de Educação. Av. Paulo da Gama 110, Reitoria, CEP: 90040-060 - Porto Alegre, Rio Grande do Sul - Brasil.

E-mail: freitascrd@gmail.com

Recebido em 16 de maio de 2013

Aprovado em 21 de setembro de 2013 
